\title{
Washingtonia robusta: Mexican Fan Palm ${ }^{1}$
}

\author{
Timothy K. Broschat ${ }^{2}$
}

The Mexican fan palm is a fast-growing species that can reach heights of 70 to 100 feet, making it too tall for typical residential landscapes. It is native to northern Mexico but grows well in Florida, being hardy down to about $20^{\circ} \mathrm{F}$ or USDA hardiness zone 9A. This species readily hybridizes with the closely related California fan palm (Washingtonia filifera), a shorter, stockier species that is poorly adapted to Florida's climate. Mexican fan palms grow well in a wide range of soils in Florida, but do require good drainage. Though considered a desert palm, it is native to areas having permanent surface or subsurface water and thus is not as drought tolerant as might be expected.

Mexican fan palm leaves are fan-shaped, about 3 to 5 feet wide, and have sharply toothed petioles about 4 to 6 feet long. Leaf bases are split and reddish-brown in color. Healthy specimens will have full, rounded canopies with at least 30 leaves, but potassium (K) deficiency typically reduces the number of leaves to half or less of that number (Fig. 1). They can produce up to 50 leaves per year. In Florida, young Mexican fan palms will retain their old leaves (or old leaf bases if the leaves have been cut off) for a number of years, resulting in a skirt of old dried leaves hanging around the trunk (Fig. 2). Once the palms reach about 30 feet in height they typically drop their old leaves or leaf bases within a period of a year or two (Fig. 3). Once that occurs these palms essentially become "self-cleaning" and do not require manual removal of old leaves. Trunks of this species are reddish-brown in color, but weather to a light gray over time. They taper from nearly 2 feet in diameter at the base to as little as 8 inches near the top of older specimens. Although palms generally survive hurricanes better than broadleaf trees, Mexican fan palms are more prone to snapping or uprooting during severe storms than other palm species.

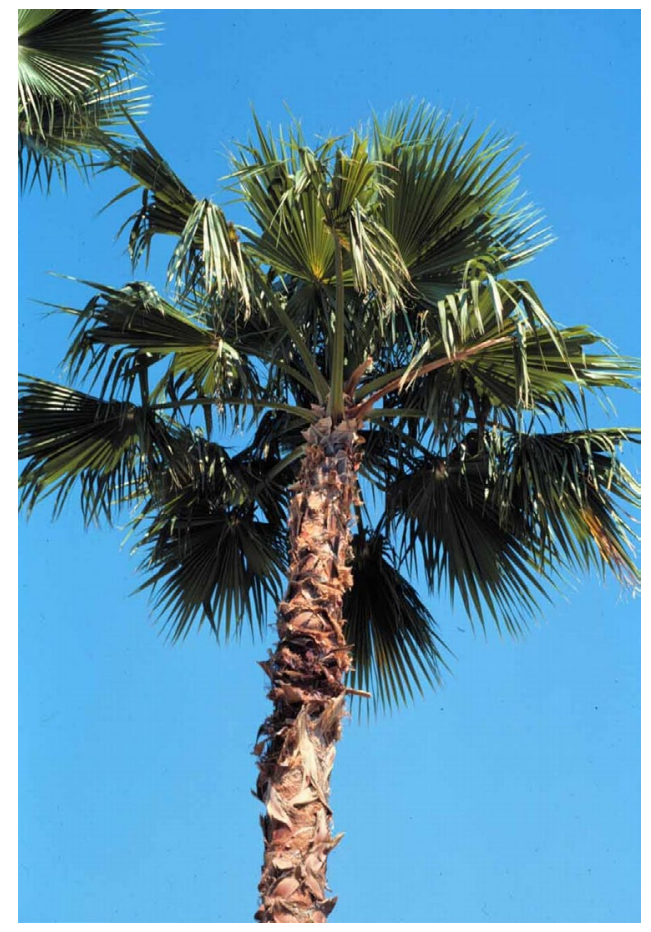

Figure 1. A typical Washingtonia robusta with less than a full $360^{\circ}$ canopy.

Credits: Timothy K. Broschat

Long pendulous inflorescences extend out from among the leaves in the spring and are followed by small (3/8 inch) black fruits later in the summer. The seeds germinate within

1. This document is ENH-827, one of a series of the Environmental Horticulture, UF/IFAS Extension. Original publication date November 1993. Revised February 2013. Visit the EDIS website at http://edis.ifas.ufl.edu.

2. Timothy K. Broschat, professor, Environmental Horticulture Department, Ft. Lauderdale Research and Education Center (FLREC), UF/IFAS Extension, Gainesville, FL 32611. 


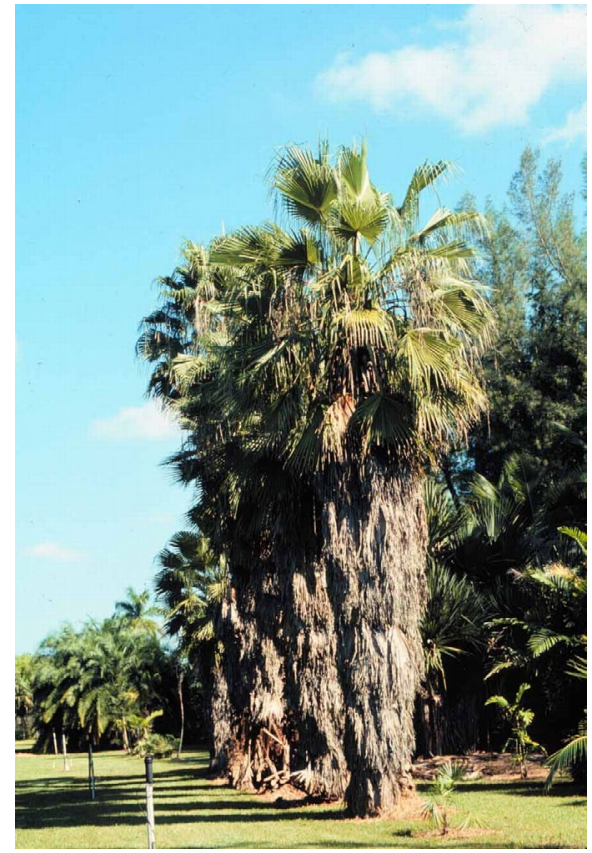

Figure 2. Washingtonia robusta with skirt of dead leaves. Credits: Timothy K. Broschat

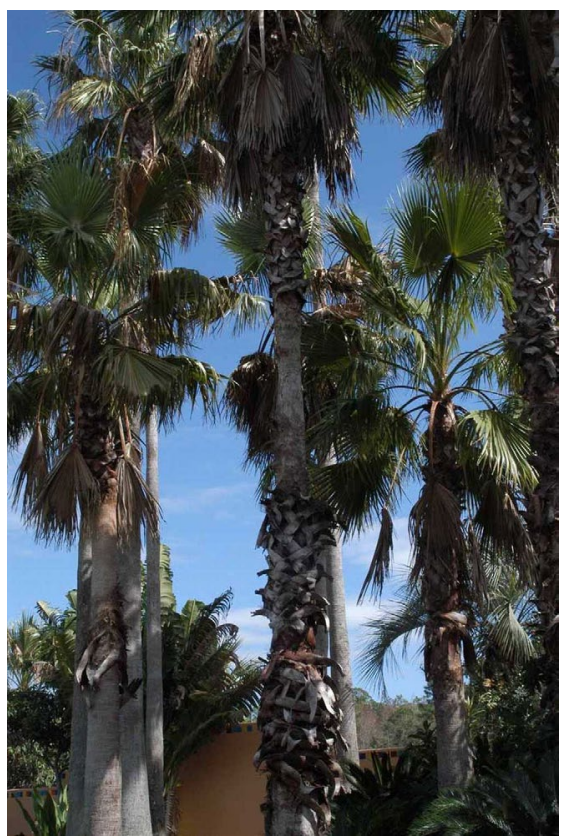

Figure 3. Leaf bases being shed from trunk of Washingtonia robusta. Credits: Timothy K. Broschat

about two weeks under warm $\left(85^{\circ} \mathrm{F}-95^{\circ} \mathrm{F}\right)$ and uniformly moist conditions. See "Palm Seed Germination" for more information about germinating palm seeds.

Mexican fan palms transplant easily as mature specimens, with root balls 6 to 12 inches from the trunk being adequate to insure good survival rates. See "Transplanting Palms in the Landscape" for more information about transplanting large specimen palms.
There are relatively few nutritional problems of concern on Mexican fan palms. Potassium (K) deficiency is virtually ubiquitous in this species, where it causes leaflet tip necrosis, leaf discoloration, and premature death of the oldest leaves (Fig. 4). Avoid removing discolored and partially necrotic older leaves because these function as supplementary sources of $\mathrm{K}$ for the palm in the absence of sufficient $\mathrm{K}$ in the soil. Proper fertilization with a controlled release 8-2-12-4 Mg plus micronutrients fertilizer will slowly increase the number of leaves in the canopy, but symptomatic older leaves will always be present until a full $360^{\circ}$ canopy of green leaves has been achieved. Depending on the severity of the $\mathrm{K}$ deficiency, that may require 3 or more years of heavy fertilization. See "Fertilization of Field-grown and Landscape Palms in Florida" for more information about palm fertilization. The only other nutritional deficiency likely to be encountered is boron (B) deficiency, which causes small, crumpled new leaves to be produced in this species (Fig. 5).

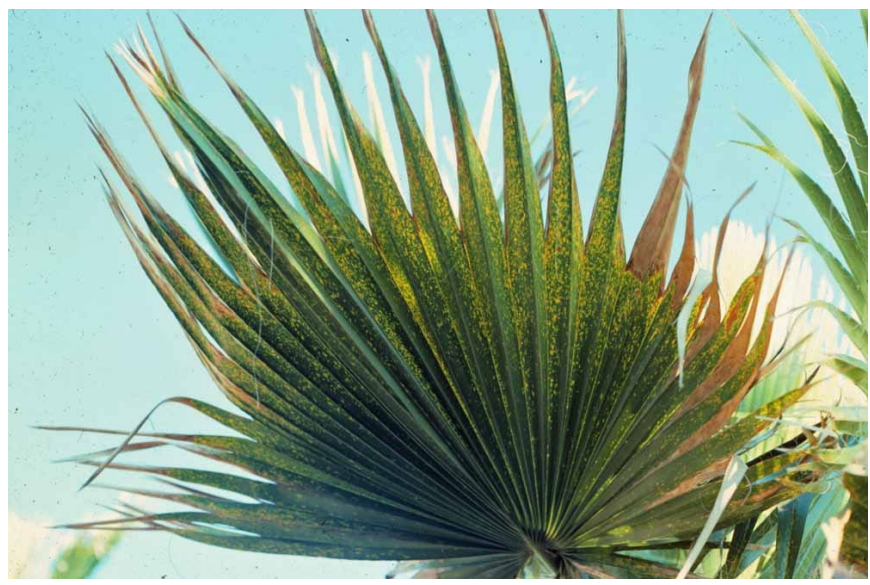

Figure 4. Older leaf of potassium-deficient Washingtonia robusta. Credits: Timothy K. Broschat

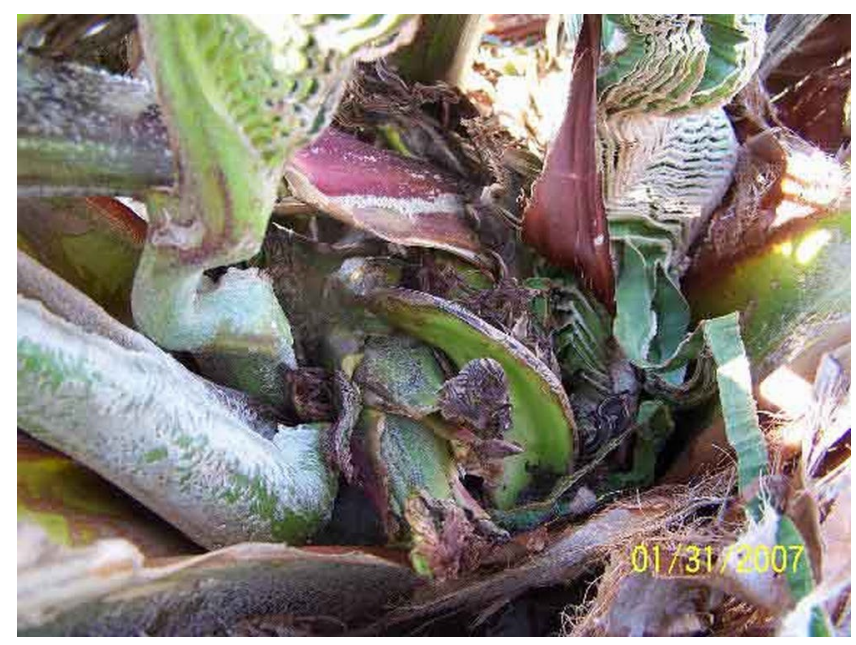

Figure 5. Crumpled new leaves of boron-deficient Washingtonia robusta.

Credits: Timothy K. Broschat 
Mexican fan palms are susceptible to a number of diseases, most of which are lethal. Mature specimens can be killed by Ganoderma butt rot, a basal trunk rot caused by Ganoderma zonatum. This soil-borne fungus infects the central bottom part of the trunk first, spreading upward and outward within the trunk. After about $80-90 \%$ of the trunk cross sectional area in the lower 3-5 feet of the trunk has been destroyed, the palm canopy will begin to lose leaves at a rapid rate and may show signs of wilting. Shelflike fruiting structures called conks may or may not emerge from the lower part of the trunk before the palm dies. These conks start out as white lumps that look like hard marshmallows but eventually develop their characteristic shelf-like shape and reddish-brown-topped color pattern. When mature, these conks release millions of rust-colored dust-like spores that are easily dispersed by the wind. There are no controls for this disease, nor are there any environmental factors known to either promote or suppress this disease. See "Ganoderma Butt Rot of Palm" for additional information about this disease.

Another trunk rotting fungus Thielaviopsis paradoxa affects only the upper portion of the trunk, often just below the canopy. This fungus requires a wound to gain entrance but then rapidly rots through the trunk until the trunk can no longer support the canopy and collapses (Figs. 6 and 7). Wilt symptoms or large oozing trunk lesions at the point of infection may or may not precede this collapse, and thus there may be little or no warning that the palm is about to fail. There are no chemical controls for this disease, but it can largely be prevented by avoiding trunk wounding. Wounds suitable for infection by Thielaviopsis can be caused by improper pruning, climbing spikes, rough handling during transplanting, or pulling off lower leaves before they can easily be detached. See "Thielaviopsis Trunk Rot of Palm" for additional information about this disease.

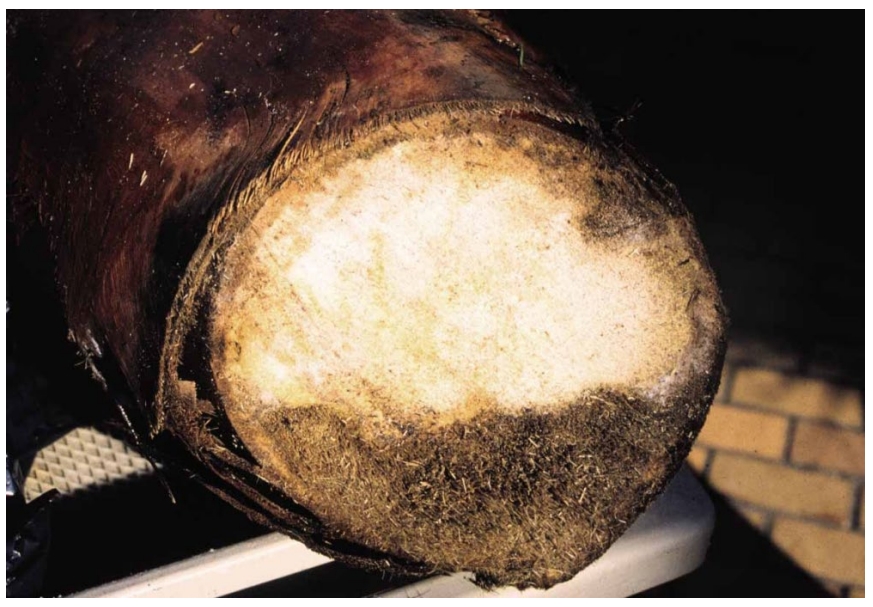

Figure 6. Cross section through trunk of Washingtonia robusta infected with Thielaviopsis paradoxa.

Credits: M. L. Elliott

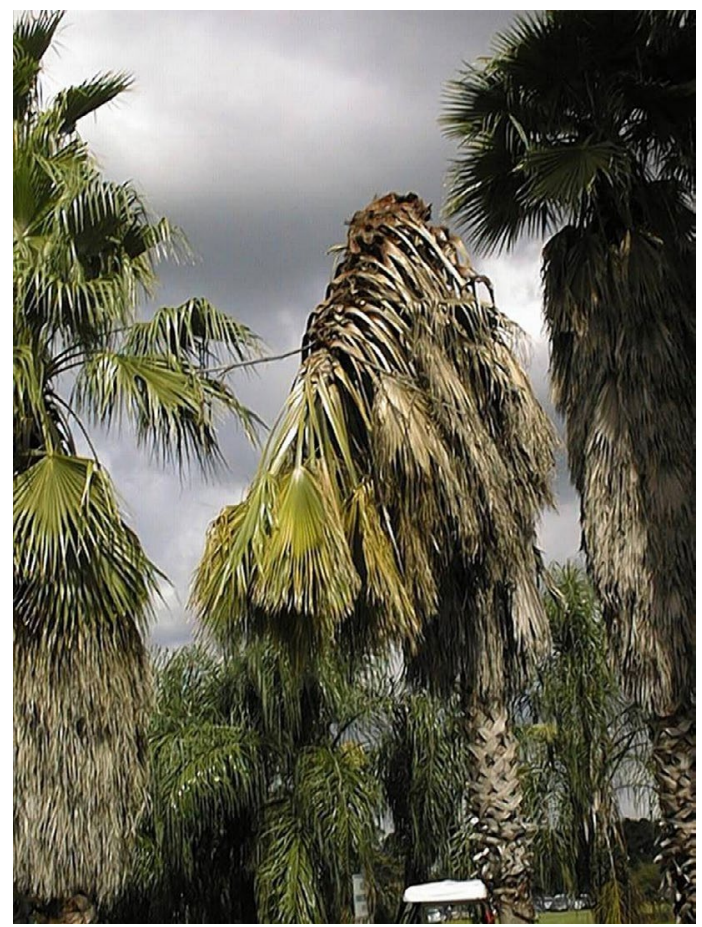

Figure 7. Collapse of a Washingtonia robusta caused by Thielaviopsis trunk rot.

Credits: F. W. Howard

Young Mexican fan palms are quite susceptible to Phytophthora bud rot, but this is seldom seen in palms with visible trunks. Although this disease starts out as a leaf spot on the spear leaf, these early symptoms are often overlooked, and the first symptom observed is usually a declining or dead spear leaf (Fig. 8). The bud dies soon after the spear leaf, but the older leaves typically linger for several months longer. This disease, caused by Phytophthora palmivora, is more prevalent in nurseries than in the landscape. See "Bud Rot of Palm" for more information about this disease.

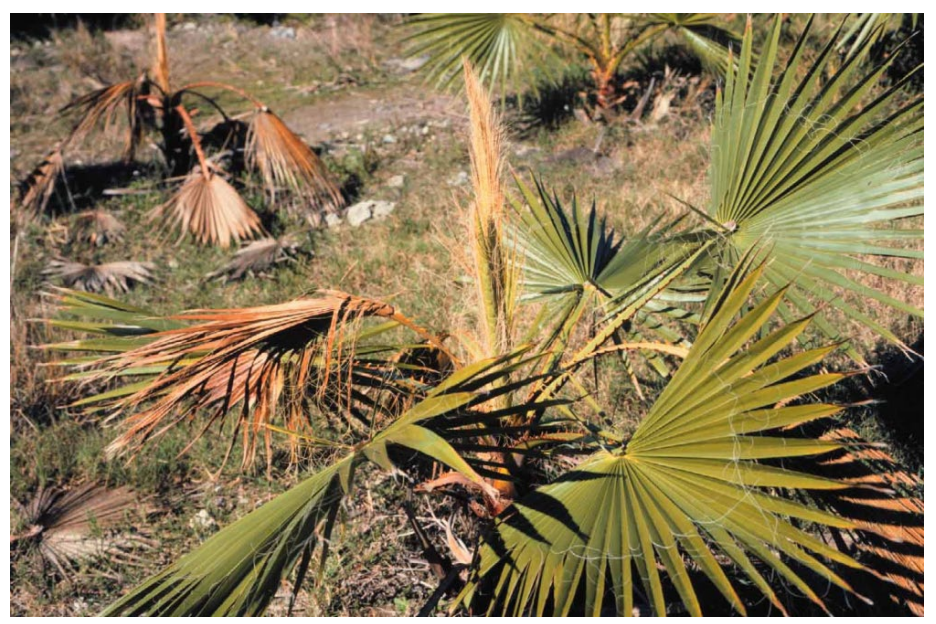

Figure 8. Phytophthora bud rot in a field nursery of young Washingtonia robusta.

Credits: T. K. Broschat

Fusarium wilt, caused by the fungus Fusarium oxysporum f.sp.palmarum, is a relatively new disease found primarily 
in Florida. It causes leaf segments on one side (or occasionally the middle) of the leaf to die. A reddish-brown stripe on the petiole is typically associated with this partial leaf death (Fig. 9). Eventually, the entire leaf will die, followed by additional leaves above it (Fig. 10). Thus, the most obvious symptom is the rapid death of older leaves, and, ultimately, the entire palm (Fig. 11). Although this disease may be spread by infected pruning tools, it is believed that the primary means of spread is via wind-blown spores. There is no control for this disease. See "Fusarium Wilt of Queen and Mexican Fan Palm" for additional information about this disease.

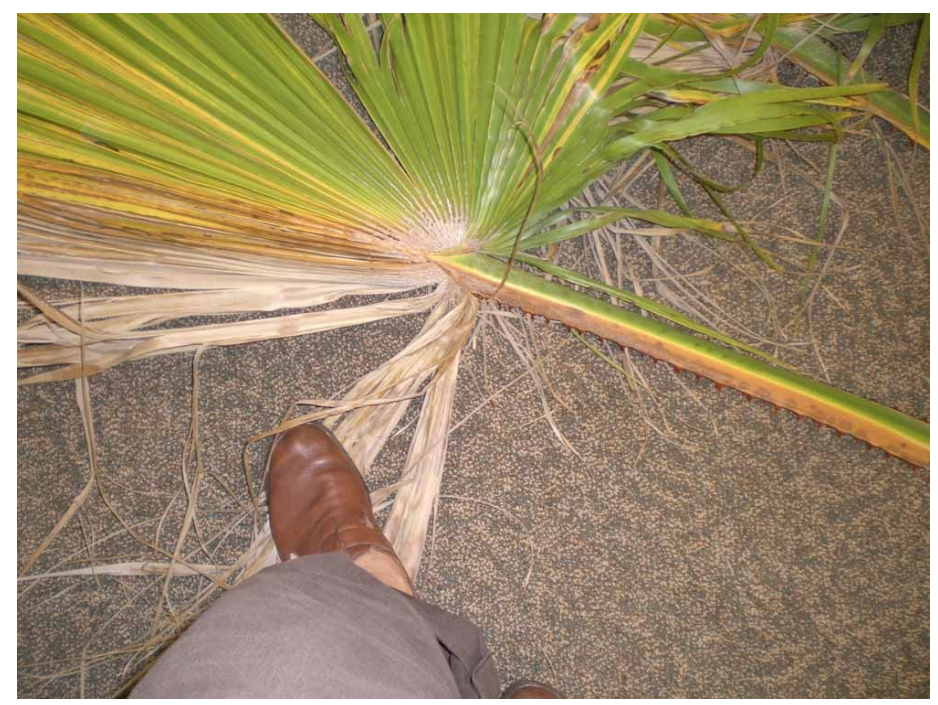

Figure 9. Petiole stripes and one-sided leaf death are characteristic symptoms of Fusarium wilt in Washingtonia robusta.

Credits: M. L. Elliott

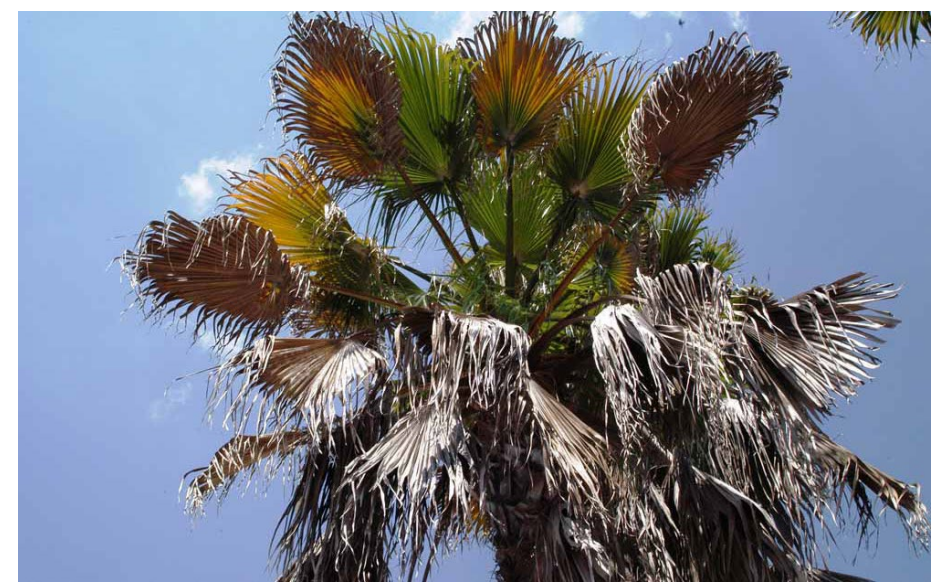

Figure 10. Rapid death of older leaves of Washingtonia robusta caused by Fusarium wilt.

Credits: M. L. Elliott

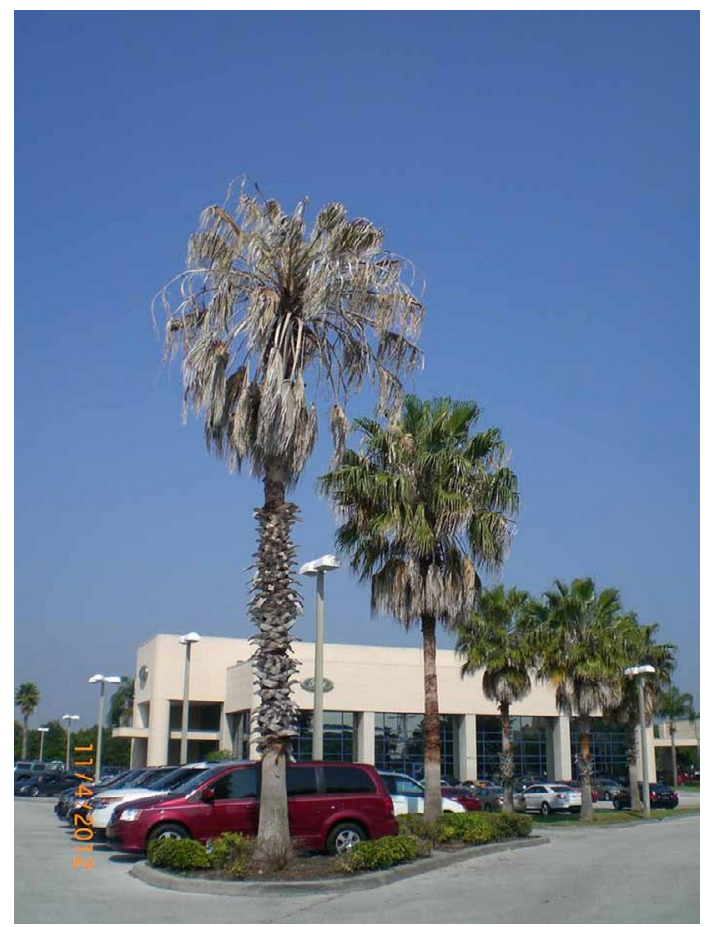

Figure 11. Dried appearance of Washingtonia robusta killed by Fusarium wilt.

Credits: M. L. Elliott

Petiole blight is a disease of Mexican fan palms with similar symptoms as Fusarium wilt, but it is not lethal. It can be caused by one of several genera of fungi, including Cocoicola, Serenomyces, Macrophoma, Phoma, and others. Although this disease also caused one-sided leaf death and reddish-brown petiole stripes, the stripes typically do not extend throughout the length of the petiole as they do in Fusarium wilt (Figs. 12 and 13). Petiole blight can cause extensive leaf loss in Mexican fan palms, but seldom actually kills the palms. Fungicides have not proven to be particularly effective in controlling this disease, but fortunately, it appears to be seasonal and thus tends to disappear without treatment after several months. See "Petiole (Rachis) Blight of Palm" for more information about this disease.

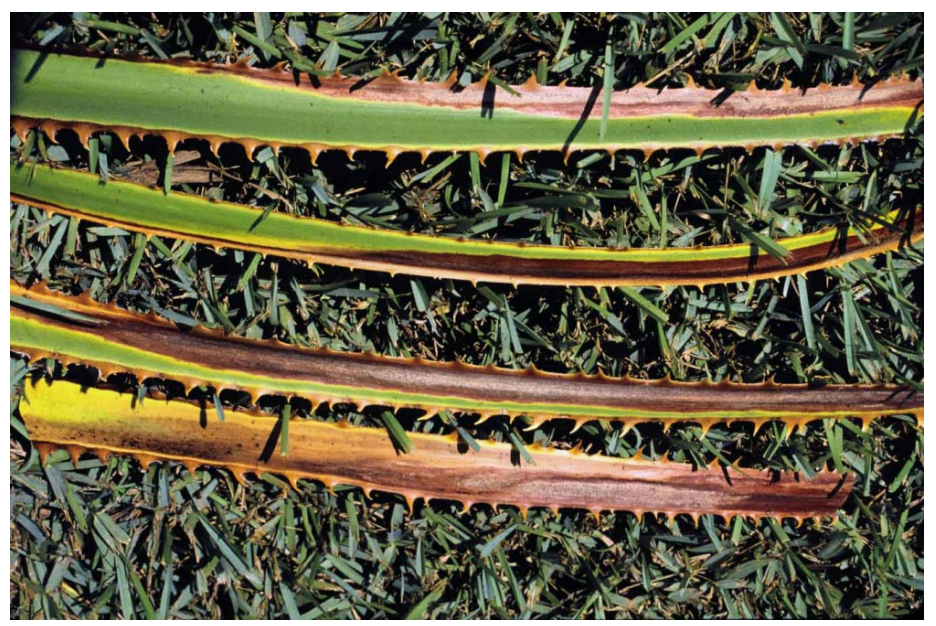

Figure 12. Petiole of Washingtonia robusta with petiole blight. Credits: Timothy K. Broschat 


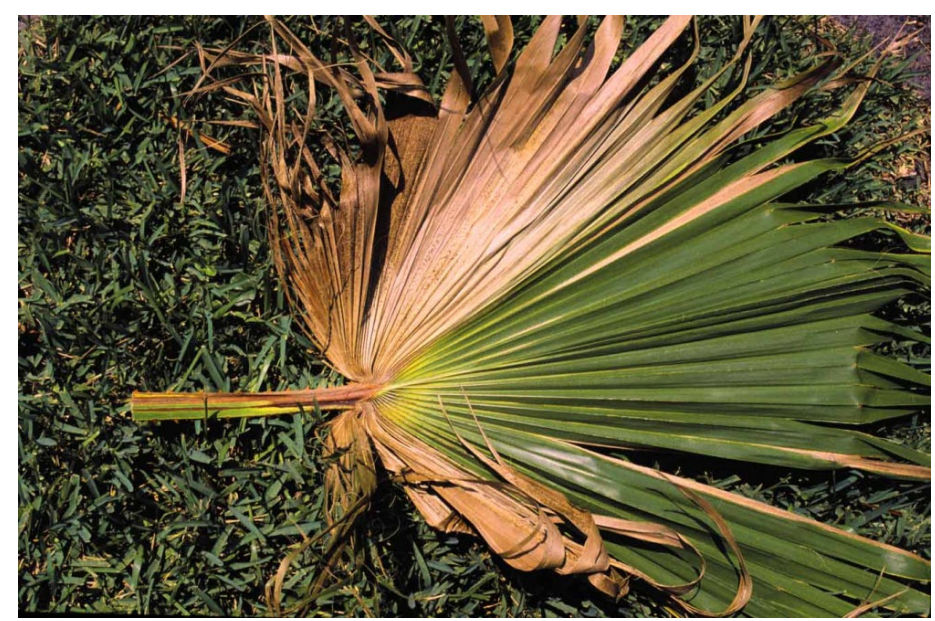

Figure 13. Leaf blade of Washingtonia robusta with petiole blight. Credits: Timothy K. Broschat

A common disorder of Mexican fan palms is an erosion of the outer portion of the trunk (Fig. 14). No pathogen has been found to be associated with this sloughing of the pseudobark and, eventually, eroding of the central cylinder of the trunk. Although some people believe that water from irrigation heads causes this problem, it also occurs on palms that do not receive irrigation.

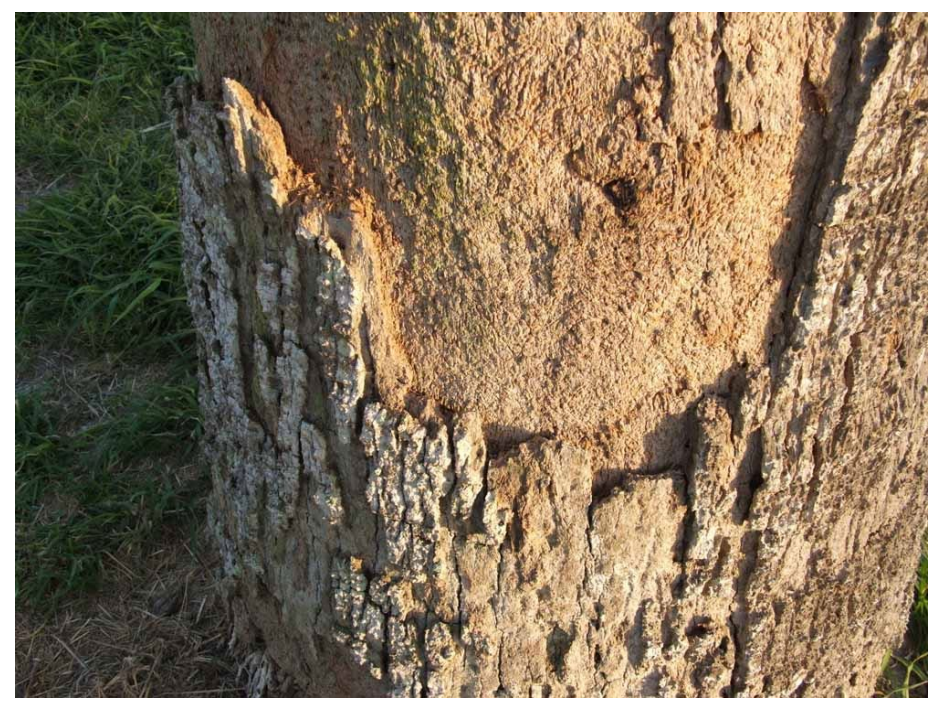

Figure 14. Trunk erosion on Washingtonia robusta.

Credits: Timothy K. Broschat

\section{References}

Broschat, T. K. and H. Donselman. 1990. "Regeneration of severed roots in Washingtonia robusta and Phoenix reclinata." Principes 34:96-97.

Elliott, M. L., T. K. Broschat, J. Y. Uchida, and G. W. Simone. 2004. "Compendium of diseases and disorders of ornamental palms." Amer. Phytopath. Soc., St. Paul, MN.

Meerow, A.W. 2006. "Betrock's landscape palms." Betrock Info. Systems, Hollywood, FL. 